\title{
Hand Hygiene of Nurses and Patient Safety
}

Maria Malliarou

Nursing Department, Technological Institution of Thessaly, Terpsithea, Larisa, 41500, Greece

\section{Abstract}

Introduction: Hand hygiene is one of the most effective measures to prevent hospital acquired infections and improve patient safety.

Aim: To state how important is for nurses to get hand hygiene in their everyday practice in order to be safe for their patients.

Method: A review of articles with key words "hand, hygiene, hand, safety, nurse, and guideline".

Results: Infectious diseases are a particular risk to the very young, the elderly, those with a pre-existing disease, and people with a compromised immune system. Nurses need to wash their hands not only to prevent them from getting sick, but to protect their patients from acquiring health-care associated infections.

\section{Publication History:}

Received: January 05, 2016

Accepted: January 11, 2017

Published: January 13, 2017

\section{Keywords:}

Hand hygiene, Hand contamination, Health careassociated infection
Hand hygiene noncompliance is a major cause of nosocomial infection. Good hand hygiene plays a major role in reducing and eliminating the spread of germs and infections from patient-topatient. Research has shown that while healthcare workers state largely favorable attitudes towards hand-cleaning practices, observed compliance rates are below 30\% [1]. Reasons given by professionals for the lack of compliance to hand-cleaning practices highlights several explanatory factors, including: work conditions (lack oftime), infrastructures (lack of equipment), training (inadequate), human environment (superiors, colleagues, unscrupulouspatients) and the health of medical and nursing staff ( skin irritations caused by frequent hand-cleaning). Infection prevention and infection control have always been serious topics, but this is particularly true today, with the spread of the swine fluand associated infections [2].

Good personal hygiene plays a major part in reducing and eliminating the spread of germs and infections from person-toperson. It also helps in reducing the spread of infectious illnesses, including colds, flu and other upper respiratory illnesses. A big part of personal hygiene is hand hygiene and incorporating safety measures in developing habits that will stave off illnesses can help to further reduce the spread of germs and infections [3]. Ensuring that today's medical professionals make hand washing a priority is essential. Simple activity of frequent hand-washing has the potential to save more lives than any single vaccine or medical intervention. It is one of the most effective and inexpensive ways to prevent diarrheal diseases and pneumonia, which cause more than 3.5 million deaths worldwide in children under the age of 5 every year. Although people around the world clean their hands with water, very few use soap to wash their hands [4].

Hand-to-hand contact can spread mild conditions, such as the common cold, but also more severe or life-threatening diseases. Infectious diseases are a particular risk to the very young, the elderly, those with a pre-existing disease, and people with a compromised immune system [5]. Nurses washing their hands not only prevent them from getting sick, but it also reduces the risk of infecting others. If they don't wash their hands properly before coming into contact with others, they can infect their patients but also their family members. The Centers for Disease Control and Prevention clearly mandates that all healthcare personnel decontaminate their hands as they enter a patient's room and as they leave the room6. The perceived barriers to hand washing that are consistently being targeted in research studies are inaccessible or inconveniently located sinks and dispensers, forgetfulness, heavy workload, ignorance of guidelines and lack of scientific knowledge. Placing dispensers immediately next to each bed is a solution to the problem or using the visual display of large posters emphasizing the importance of hand washing reminds staff to wash their hands $[7,8]$.

\section{Competing Interests}

The authors have no conflicts of interest to declare.

\section{References}

1. McGuckin M, Waterman R, GovednikJ (2009) Hand hygiene compliance rates in the United States--a one-year multicenter collaboration using product/volume usage measurement and feedback. Am J Med Qual 24: 205-213.

2. Author Unknown (2000) Surgicare. Retrieved on November 25, 2011.

3. Author Unknown (2006). Nosocomial Infection. Retrieved on November 20, 2011.

4. Centers for Disease Control and Prevention (2003) Guidelines for Environmental Infection Control in Health-Care Facilities: Recommendations of CDC and the Healthcare Infection Control Practices Advisory Committee (HICPAC). MMWR 52 (No. RR-10).

5. Pittet D, Hugonnet S, Harbarth S, Mourouga P, Sauvan V, et al. (2000) Effectiveness of a Hospital-Wide Programme to Improve Compliance with Hand Hygiene. The Lancet 356: 1307-1312.

6. Pittet D (2001) Improving Adherence to Hand Hygiene Practice: A Multidisciplinary Approach. Emerg Infect Dis 7: 234- 238.

7. Randle J, Clarke M, Storr J (2006) Hand Hygiene compliance in Healthcare Workers. Journal of Hospital Infections 64: 205-209.

8. Van Enk RA (2006) Modern Hospital Design for Infection Control. Healthcare Design Magazine, September 2006.

"Corresponding Author: Dr. Maria Malliarou, Nursing Department, Technological Institution of Thessaly, Terpsithea, Larisa, 41500, Greece, Tel: +81-95-819-2359; E-mail: mmalliarou@gmail.com

Citation: Malliarou M (2017) Hand Hygiene of Nurses and Patient Safety. In J Nurs Clin Pract 4: 217. doi: https://doi.org/10.15344/2394-4978/2017/217

Copyright: () 2017 Malliarou. This is an open-access article distributed under the terms of the Creative Commons Attribution License, which permits unrestricted use, distribution, and reproduction in any medium, provided the original author and source are credited. 